\title{
Unnoticed bilateral partial anomalous pulmonary vein connection
}

\author{
Juan Miguel Aguilar Jiménez, MD, Enrique García Torres, PhD, Francesco Arlati, MD, and \\ Juan V. Comas Íllas, PhD, Madrid, Spain
}

Partial anomalous pulmonary vein connection (PAPVC) is characterized by drainage of 1 or more pulmonary veins (but not all) into the right atrium or one of its tributary veins. Anomalous connections of the left pulmonary veins are rare. Bilateral PAPVC is extremely unusual.

We report the case of a patient who underwent surgical closure of the atrial septal defect (ASD), ventricular septal defect (VSD), and correction of the left superior pulmonary vein drainage at the age of 7 months. Subsequent postoperative controls showed no evidence of right chamber overload regression. We performed cardiac magnetic resonance imaging (MRI) that showed a PAPVC of the right superior pulmonary vein to the superior vena cava and a PAPVC of the left inferior pulmonary vein to the left suprahepatic vein through a collector.

The child underwent definitive surgical correction at the age of 5 years. Postoperative recovery was uneventful. Predischarge transthoracic echocardiogram showed an important reduction of the volume of the right chambers.

PAPVC is characterized by drainage of 1 or more pulmonary veins, but not all, into the right atrium or one of its tributary veins. It often involves the right superior pulmonary vein. Anomalous connections of the left pulmonary veins are rare. Bilateral PAPVC is extremely unusual $(1 \%-2 \%)$. Bilateral PAPVC usually involves the upper lobe of both lungs with the left superior pulmonary vein draining into the left innominate vein through an anomalous vertical vein. ${ }^{1,2}$

\section{CLINICAL SUMMARY}

We report the case of a patient with prenatal diagnosis of a large perimembranous VSD. Postnatal echocardiography revealed PAPVC of the left pulmonary veins to the innominate vein through a vertical vein, an ostium secundum ASD, and a larger perimembranous VSD.

At 7 months of age, the patient underwent surgical closure of the ASD and VSD with patches of autologous pericardium, ligation of the vertical vein, and side-to-side

From the Pediatric Heart Institute, Hospital Universitario Doce de Octubre, Madrid, Spain.

Disclosures: Authors have nothing to disclose with regard to commercial support.

Received for publication Sept 30, 2014; accepted for publication Oct 16, 2014; available ahead of print Nov 27, 2015.

Address for reprints: Juan Miguel Aguilar Jiménez, MD, Avenida de Betanzos $68.2^{\circ}$ C. 28034, Madrid, Spain. (E-mail: juanmi_ccv@hotmail.com).

J Thorac Cardiovasc Surg 2015;149:e40-2

$0022-5223 / \$ 36.00$

Copyright (C) 2015 by The American Association for Thoracic Surgery

http://dx.doi.org/10.1016/j.jtcvs.2014.10.102

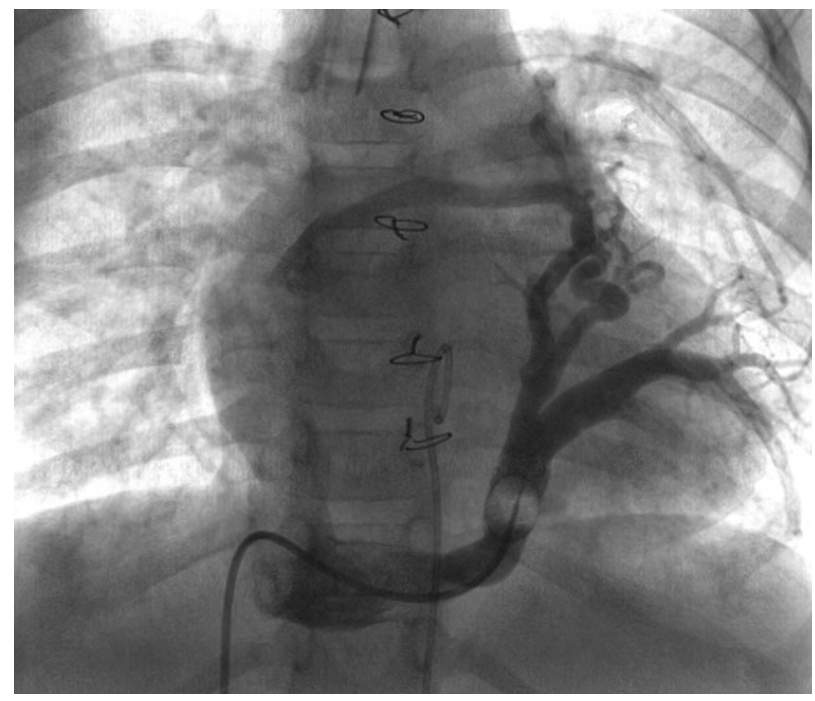

FIGURE 1. Selective stop-flow angiography at the level of the left inferior pulmonary vein draining through a collector into the left suprahepatic vein. A tortuous escape connection between the infradiaphragmatic collector and the roof of the left atrium was observed.

anastomosis between the left pulmonary vein collector and the left atrial appendage. Postoperative recovery was complicated by pulmonary edema. The patient improved with diuretic therapy and recovered well.

Because subsequent postoperative controls showed no evidence of right chamber overload regression, we performed a cardiac MRI, which showed a PAPVC of the right superior pulmonary vein to the superior vena cava and a PAPVC of the left inferior pulmonary vein to the left suprahepatic vein through a collector. In addition to normal drainage of the middle and lower right pulmonary veins, a wide and patent anastomosis between the left superior pulmonary vein and the left atrial appendage was found.

A selective stop-flow angiography at the level of the infradiaphragmatic collector displayed a wide left inferior pulmonary vein draining through a collector into the left suprahepatic vein; a tortuous escape connection between the infradiaphragmatic collector and the roof of the left atrium through was observed (Figure 1).

\section{Surgical Technique}

The child underwent definitive surgical correction at 5 years. Cardiopulmonary bypass was established with aortic cannulation and drainage of the inferior cava vein and 


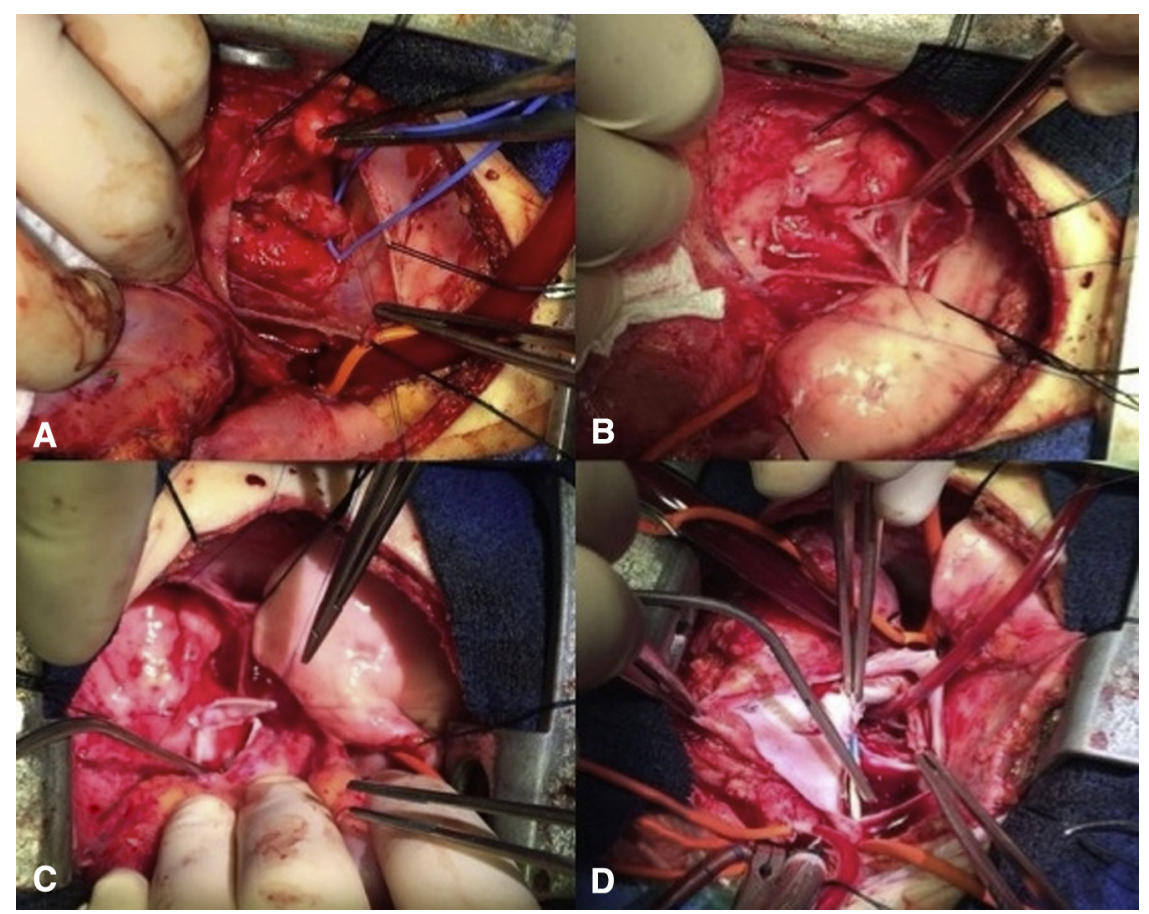

FIGURE 2. A, Dissection and control of the left inferior pulmonary vein with vessel loop. B, The collector opened longitudinally. C, Collector left atrium anastomosis. D, Right atriotomy parallel to the atrioventricular groove extended to the lateral aspect of the superior vena cava. Collector left atrium anastomosis through the ASD and vacuum pump inside the right superior pulmonary vein.

innominate vein. During deep hypothermic circulatory arrest, the cardiac apex was retracted cephalad and rightward, and the posterior pericardium was opened to proceed to dissection of the collector of the left inferior pulmonary vein immediately above the diaphragm. The collector was opened longitudinally and sutured to the left atrium with a latero-lateral anastomosis (Figure 2, $A-C$ ).

Cardiopulmonary bypass was reestablished, and progressive warming was begun. Correction of PAPVC to the superior vena cava was done through a right atriotomy parallel to the atrioventricular groove extended to the lateral aspect of the superior vena cava. The atrial septum was opened, and the right superior pulmonary vein was tunnelized to the left atrium by means of a heterologous pericardium patch (Figure 2,D). The atriotomy was closed with an enlargement plasty with a $0.4-\mathrm{mm}$ polytetrafluoroethylene patch. Postoperative recovery elapsed uneventfully with discharge on day 4 with the patient in sinus rhythm.

Predischarge transthoracic echocardiogram showed an adequate draining of the right superior pulmonary into the left atrium through the tunnel and a patent anastomosis between the left atrium and the left inferior pulmonary vein. Peak velocity and average gradient of both anastomoses were $1 \mathrm{~m} / \mathrm{s}$ and $1 \mathrm{~mm} \mathrm{Hg}$, respectively. An important reduction of the volume of the right chambers also was observed.

\section{DISCUSSION}

This is a rare case of bilateral PAPVC characterized by PAPVC of the left superior pulmonary vein into the innominate vein, anomalous right superior pulmonary vein drainage into the superior vena cava, and left inferior pulmonary vein connection to the left suprahepatic vein. These 2 latter anatomic features were not diagnosed before the first surgery. The correct anatomic pattern was discovered on MRI because of persistent overload of the right chambers.

Identification of PAPVC by echocardiography can be difficult. ${ }^{3}$ It is important to perform MRI in case of persistent overload of the right chambers after surgery. The second surgery was performed with the intracaval tunnel technique. This technique has been associated with risk of sinus node dysfunction by injury of the sinus node and its artery. ${ }^{4}$ Other series have shown minimal or no impact on sinusal dysfunction. ${ }^{5}$ In our case, we observed a transient sinus node dysfunction in the immediate postoperative period; sinus rhythm was registered at discharge.

\section{CONCLUSIONS}

A straight preoperative anatomic assessment of the PAPVC is mandatory. If any doubt persists, additional investigations (eg, MRI) are needed. Likewise, an extensive and precise intraoperative identification of the pulmonary 
venous return anatomy plays a pivotal role in the management of these patients.

\footnotetext{
References

1. Alsoufi B, Cai S, Van Arsdell GS, Williams WG, Caldarone CA, Coles JG. Outcomes after surgical treatment of children with partial anomalous pulmonary venous connection. Ann Thorac Surg. 2007;84:2020-6.

2. Marianeschi SM, Cannata A, Uricchio N, Pedretti S, Vignati G. Partial anomalous connection of both superior pulmonary veins. Ann Thorac Surg. 2012;94:649-51.
}

3. White CS, Baffa JM, Haney PJ, Pace ME, Campbell AB. MR imaging of congenital anomalies of the thoracic veins. Radiographics. 1997;17: 595-608.

4. Buz S, Alexi-Meskishvili V, Villavicencio-Lorini F, Yigitbasi M, Hübler M, Weng Y, et al. Analysis of arrhythmias after correction of partial anomalous pulmonary venous connection. Ann Thorac Surg. 2009;87:580-3.

5. Gokaslan G, Ustunsoy H, Deniz H, Baspinar O, Guzel G, Ozcaliskan O, et al. Lateral cavoatriotomy for partial anomalous pulmonary venous connection to the superior vena cava. Ann Thorac Cardiovasc Surg. 2013; 19:216-21.

\title{
Living related donor middle lobe lung transplant in a pediatric patient
}

\author{
Takahiro Oto, MD, Kentaroh Miyoshi, MD, Seiichiro Sugimoto, MD, and Masaomi Yamane, MD, \\ Okayama, Japan
}

There are 2 major problems with the availability of lung transplants for very young patients. Younger donors are limited; only 394 of 25,874 donors $(1.5 \%)$ in the United States and 1 of $251(0.4 \%)$ in Japan were 5 years old or younger. ${ }^{1-3}$ There are significant size discrepancies between older donors and very young recipients. These problems have been addressed by living related donor lower lobe lung transplants for critically ill children. ${ }^{4}$ Adult lower lobe grafts, however, may be too large for a small toddler's chest. Living related donor middle lobe transplants would seem ideal, but this graft has been considered inadequate for transplant. ${ }^{5}$ This report describes the first successful living related donor middle lobe lung transplant in a very young patient.

The recipient was a 3-year-old boy (height, $91 \mathrm{~cm}$; weight, $12 \mathrm{~kg}$ ) with a combination of obstructive and restrictive lung dysfunction as a result of graft-versus-host disease after a bone marrow transplant at the age of 1 year. The patient required in-hospital intensive care as a result of dyspnea and repeated pneumomediastinum (Figure 1, $A$ and $C$ ). The patient was thought to be unable to survive long enough for a size-matched brain-dead pediatric donor lung to become available in Japan. Living

From the Department of Thoracic Surgery, Okayama University Graduate School of Medicine, Dentistry and Pharmacological Sciences, Okayama, Japan.

Disclosures: Authors have nothing to disclose with regard to commercial support.

Received for publication Aug 13, 2014; revisions received Oct 20, 2014; accepted for publication Oct 25, 2014; available ahead of print Nov 27, 2015

Address for reprints: Takahiro Oto, MD, 2-5-1, Shikata-cho, Kita-ku, Okayama 7008558, Japan (E-mail: oto@md.okayama-u.ac.jp).

J Thorac Cardiovasc Surg 2015;149:e42-4

$0022-5223 / \$ 36.00$

Copyright (c) 2015 by The American Association for Thoracic Surgery

http://dx.doi.org/10.1016/j.jtcvs.2014.10.102 related donor lobar lung transplant was considered as an alternative therapy. The recipient's mother seemed the best immunologic candidate as lung donor, because she had donated her bone marrow to her son. Computed tomography revealed that the volumes of the donor's lower and middle lobes were estimated to be $544 \%$ and $216 \%$ larger than that of the recipient hemithorax, respectively. Threedimensional computed tomography also revealed that the middle lobe had single pulmonary arterial, venous, and bronchial branches, and there were no other small branches. The middle lobe lung transplant was therefore planned, and informed consent was obtained. This procedure was approved by the institutional ethics board of Okayama University.

\section{CLINICAL SUMMARY \\ Donor Operation}

Because the middle lobe had single pulmonary arterial, venous, and bronchial branches, no vascular or bronchial reconstruction was required for the donor operation.

\section{Recipient Operation}

After right pneumonectomy, the middle lobe graft was rotated $45^{\circ}$ clockwise and was fitted into the recipient chest cavity. All the vascular and bronchial anastomoses were performed in an end-to-end fashion. The middle lobe bronchus was trimmed as short as possible to avoid torsion of the implanted lobe and was anastomosed to the recipient's right main bronchus. After completion of the bronchial anastomosis, the middle lobe graft was inflated for inspection of positional relationship. The middle lobe vein was then anastomosed to the recipient's right upper vein. Pulmonary arterial anastomosis was the most challenging part. Because the middle lobe artery took 